\title{
OFFSPRING SEX RATIO AND AGE OF PARENTS
}

\author{
GRAEME CAUGHLEY \\ School of Biological Sciences, Zoology Building, \\ University of Sydney
}

(Received 10th November 1970)

Kamaljan (1962) suggested that the age of parents might influence the sex ratio of offspring. His data from man, cattle, pigs and horses were consistent with the hypothesis that parents of intermediate ages produce a greater proportion of female offspring than do younger or older parents. Lowe (1969) and Meadows (1969) implied that the differences Kamaljan reported were statistically significant. Further, Lowe (1969) examined data from red deer, Cervus elaphus, for such an effect, found it, and constructed fecundity tables on the assumption that females between 5 and 8 years of age produce more female than male offspring.

If this effect is real and general, most current models of mammalian population dynamics will require modification. Before such a large step is taken, it might be as well to re-examine the evidence on which the hypothesis is based.

Kamaljan (1962) presented sex ratios of offspring classified by age of both parents. Parents were divided into 'young', 'intermediate' and 'old', the interval of years these classes represent being given for each species in Table 1. Table 2 shows the $\chi^{2}$ values of association between sex ratio of the offspring and the age of the parents. Each results from a $2 \times 3$ contingency test, the three age-classes of parents being those in Table 1 . Since each test has two degrees of freedom, a $\chi^{2}$ of at least 5.99 is required before an association is acceptable at the $5 \%$ level of significance. Of the ten examples, only one comparison (age of male parent against sex ratio of first-born offspring in man) reached the required level.

In each of Kamaljan's examples, parents of intermediate ages produced offspring whose sex ratio was biassed further towards females than was the sex ratio of offspring produced by younger or older parents. This provides strong evidence in favour of the hypothesis, regardless of the general lack of significance shown by individual examples. There is, however, an alternative explanation. When sampling variation is high consequent on low numbers, it is possible unconsciously to choose a set of contiguous ages of parents whose offspring have a sex ratio deviating from the mean, as may have happened here. Table 1 shows inconsistency in Kamaljan's choice of an intermediate-age set. That for male cattle is narrower than for females, in pigs it is broader for males, and in horses the intermediate age interval is the same for both parental sexes. Even so, the subjectivity evident in the choice of age intervals should have little effect if the number of offspring is large. But, in the present case, subjectivity of selection cannot be ignored as a possible influence on the results: the ranks of 
the number of offspring used in a test (Table 2) are correlated negatively with the ranks of the resultant $\chi^{2}$ values. Hence, the evidence tends to become stronger as the data become fewer, an effect that casts doubt on the results.

Lowe (1969) presumed that the ages from 5 to 8 years were 'intermediate' for female red deer. He compared the sex ratio of foetuses produced by females in this age interval with the sex ratio of foetuses produced by all other ages. The

TABLE 1

AGE GLASSES DEFINED BY KAMALJAN

\begin{tabular}{l|c|c|c|c}
\hline \multirow{2}{*}{ Species } & \multirow{2}{*}{ Sex } & \multicolumn{3}{|c}{ Age intervals (years) } \\
\cline { 2 - 5 } & & Young & Intermediate & Old \\
\hline Man (A)* & M & $<25$ & 25 to 39 & $>39$ \\
Man (B) $\dagger$ & F & $<25$ & 25 to 34 & $>34$ \\
& M & $<25$ & 25 to 34 & $>34$ \\
Cattle & F & $<20$ & 20 to 29 & $>29$ \\
Pig & M & $<4$ & 4 to 6 & $>6$ \\
& F & $<4$ & 4 to 8 & $>8$ \\
Horse & M & $<2$ & 2 to 6 & $>6$ \\
& F & $<2$ & 2 to 5 & $>5$ \\
& M & $<6$ & 6 to 9 & $>9$ \\
& F & $<6$ & 6 to 9 & $>9$ \\
\hline
\end{tabular}

* Parents of firstborn excluded.

† Only parents of firstborn.

TABLE 2

ASSOCIATION OF OFFSPRING SEX RATIO WITH AGE OF PARENTS*

\begin{tabular}{l|c|c|c}
\hline \multirow{2}{*}{\multicolumn{1}{c|}{ Species }} & \multirow{2}{*}{$\begin{array}{c}\text { No. of } \\
\text { offspring }\end{array}$} & \multicolumn{2}{|c}{ Heterogeneity $\chi^{2} \dagger$} \\
\cline { 4 - 4 } & & By mother & By father \\
\hline Man (A) & 3650 & $1 \cdot 22$ & 0.62 \\
Man (B) & 1943 & 1.82 & $9 \cdot 22$ \\
Cattle & 4860 & $1 \cdot 15$ & $2 \cdot 71$ \\
Pig & 29912 & 1.26 & 0.87 \\
Horse & 3399 & $2 \cdot 28$ & 1.60 \\
\hline
\end{tabular}

* Analysis of data presented by Kamaljan (1962).

$\uparrow P$ is less than 0.05 when $\chi^{2}$ is greater than 5.99.

observed difference-a greater proportion of female foetuses produced by mothers of intermediate ages-was significant by signed-rank testing. If the difference is real, it should be demonstrable also by routine heterogeneity $\chi^{2}$ testing that requires no prior selection of age classes designated 'intermediate'. Lowe's Table 15 presents the sexes of 245 foetuses classified by the year-class of the mothers. When these data are analysed as they stand, no dependence of foetal sex ratio on age of mother can be demonstrated $\left(\chi^{2}=8.02\right.$, d.f. $=8$, $P=0.4$ ).

The purpose of this note is not to disprove the hypothesis that the sex ratio of the offspring depends on the age of the parents, but to point out, first, that 
evidence advanced in its favour is far from conclusive, and second, that a logically valid test of the hypothesis is not possible if an intermediate-age set is selected before testing.

\section{REFERENCES}

Kamaljan, V. S. (1962) The effect of parental age on the sex ratio of offspring. Zh. obshch. Biol. 23, 455. Lowe, V. P. W. (1969) Population dynamics of the red deer (Cervus elaphus L.) on Rhum. F. Anim. Ecol. $38,425$.

Mzadows, B. S. (1969) Sex ratios. New Scient. 44, 476. 